\title{
Successful Horn Amputation for the Treatment of Horn Cancer in an 18 Year Old Humped Bullock
}

\author{
Harmanpreet Singh Sodhi* and Vandana Sangwan
}

Department of Veterinary Surgery and Radiology, College of Veterinary Science, Guru Angad Dev Veterinary and Animal Sciences University, Ludhiana-141004, Punjab, India

*Corresponding author

\section{A B S T R A C T}

Keywords

Horn Amputation, Treatment, Horn cancer

Article Info

Accepted:

07 July 2019

Available Online:

10 August 2019
The report describes a case of unilateral (right) horn cancer in a humped bullock of age 18 years. The horn was bent downwards and was soft at the base. Radiography in frontal view revealed soft tissue density in the affected cornual sinus compared to air in the normal horn. The affected horn was surgically amputated and the sinuses were thoroughly flushed using suction under general anesthesia. The bullock recovered uneventfully from anesthesia. Telephonic follow up upto 10th postoperative day revealed the bullock to be healthy but, the condition deteriorated slowly and the bullock died within 20 days. Histopathology confirmed the condition to be squamous cell carcinoma of horn.

\section{Introduction}

Horn cancer is common in bullocks with larger horns, affecting approximately one percent of population in India. Horn cancer is usually unilateral (Giri et al., 2011 and Veena et al., 2011) and is mostly encountered in cattle of 5-10 years of age (Tyagi and Singh, 2006).

The condition is reported to be associated with chronic irritation of horns at the base (Sastry, 2001). The most commonly observed clinical signs are frequent head shaking, tilting at the affected side, bending of affected horn and nasal discharge in advance cases (Joshi et al.,
2009). The bullocks appear to be highly susceptible as compared to bulls and cows. Carcinoma of horn core in cattle is primarily squamous cell neoplasm (Patra, 1963).

For the treatment of horn cancer, amputation of horn is recommended. Few reports of chemotherapy along with amputation are also reported (Udharwar et al., 2008).

With the decrease in draft bullocks due to mechanization and horn disbudding at early age, the condition is less reported nowadays. The present case describes the successful surgical amputation of affected horn in a humped bullock under general anesthesia. 


\section{History and symptoms}

An Indian humped bullock of 18 years of age, weighing $430 \mathrm{Kgs}$, was presented with the bending of right horn from the base from the last 6 months (Fig. 1). Clinical examination revealed the base of the horn to be soft with foul smell coming from it. There was a history of injury 10 days back, which led to further deterioration of the condition. The bullock was being used for draft purpose. Radiography in frontal view revealed soft tissue density in the affected horn sinus compared to air in the healthy horn sinus (Fig. 2).

The soft tissue density was suspected to be tumorous tissue or pus accumulated in the cornual sinus. Explaining the surgical risk involved and the possible prognosis of the surgery, consents for horn amputation under general anesthesia were taken from the owner. The bullock was given an antibiotic course of 5 days and the owner was advised to bring the bullock on the day of surgery by keeping 24 hours off-feed and off water.

\section{Treatments and Discussion}

The bullock was restrained in lateral recumbency with the right side upwards. The surgical site was prepared for aseptic surgery. Intravenous fluid line was maintained and the pre-anesthetic inj. xylazine @ $0.025 \mathrm{mg} / \mathrm{kg}$ was given intravenously. Induction was done using inj. ketamine @5mg/kg, intravenously. Endotracheal intubation was done with ET no. 22 and the anesthesia was maintained using isoflurane mixed in $100 \%$ oxygen. The incision was given at the base of the horn in an elliptical manner, saving maximum possible skin. The skin was undermined for the loosening and exposure of skull bone. The two-third of the horn was soft and was removed using scalpel. The rest of the horn base required separation using chisel and hammer. Being abnormal, no specific vessels were seen to be ligated. The bleeding was controlled using artery forceps or pressure with gauze pieces. The part of skull bone at the base was evenly chiseled out using chisel and hammer to make space for skin suturing. The tissue growth and the thick pus were removed from the frontal sinus (Fig. 3) using gauzes and were flushed with normal saline solution and suction. The skin was sutured using cross mattress suture pattern with silk No.2.Immediate post operatively, there was no bleeding and the bullock recovered smoothly from anesthesia.

Post-operative care included antibiotics inj. Ampicillin and Cloxacillin @10mg/kg, twice daily for 5 days, and inj. Meloxicam @0.2 $\mathrm{mg} / \mathrm{kg}$ once daily for 3 days, intramuscular. Daily dressing of the suture line was advised with $0.1 \%$ Povidone iodine solution and fly repellant spray. The skin sutures were advised to be removed on 15 th post-operative day. Telephonic follow up upto 10thpostoperative day revealed the bullock to be healthy (Fig. 4). But, the condition slowly deteriorated and the bullock died within 20 days. The sample of the tissue removed from the sinus was sent for histopathology. Histological examination was suggestive of squamous cell carcinoma.

The recovery in such cases has been reported to be successful (Giri et al., 2011; Jaiswal et al., 2014; Sharma and Singh,2014; Pitlawar et al., 2016; Behera et al., 2016), although in the present case the surgery was successful but the bullock died within 20 days of surgery, possibly due to old age and chronic weakness. Carcinoma of horn core in cattle is primarily squamous cell. Histological examination of squamous cell carcinoma had typical keratinizing squamous cell with characteristic epithelial pearls (Giri et al., 2011; Jaiswal et al., 2014; Kumar et al., 2013; Pitlawar et al., 2016 and Behera et al., 2016). The basic difficulty in the removal of horn for horn cancer is to find healthy skin for skin sutures. 
Fig.1 Photograph showing the clinical presentation of the bullock with the bending of the right horn (yellow arrow)

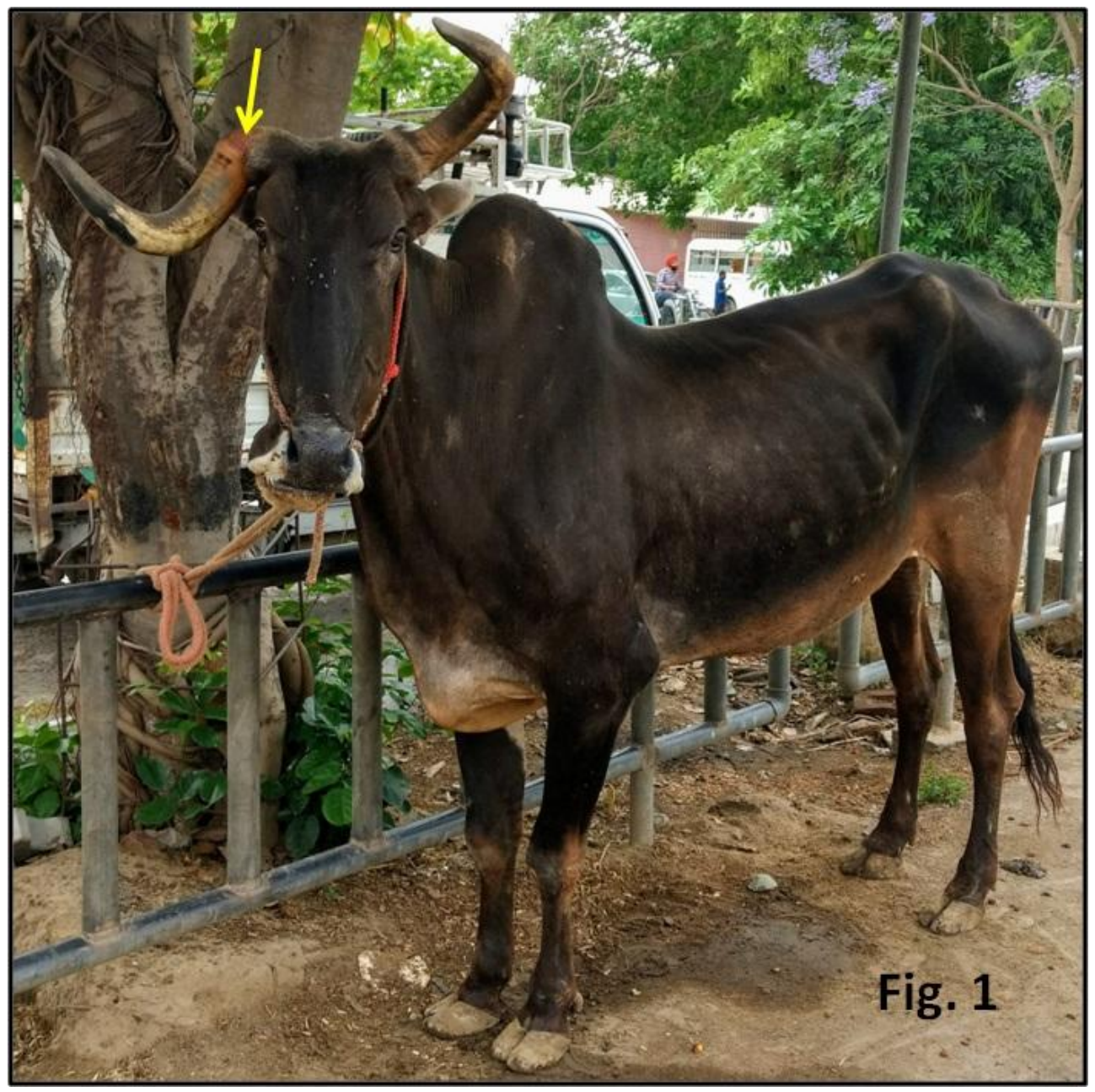

Fig.2 Frontal view of radiograph showing soft tissue density in the right horn sinus (yellow arrow) while normal air density on the left side

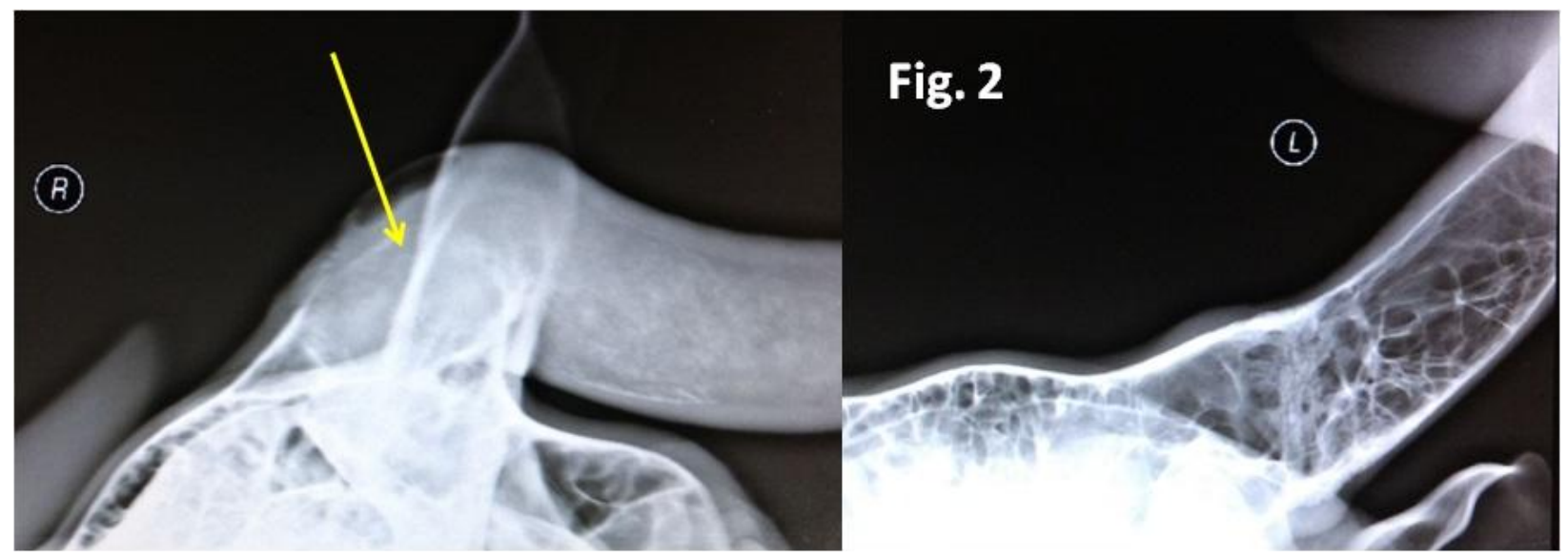


Fig.3 Photograph showing amputated horn base with thick yellow pus in the Corneal sinus (black arrow)

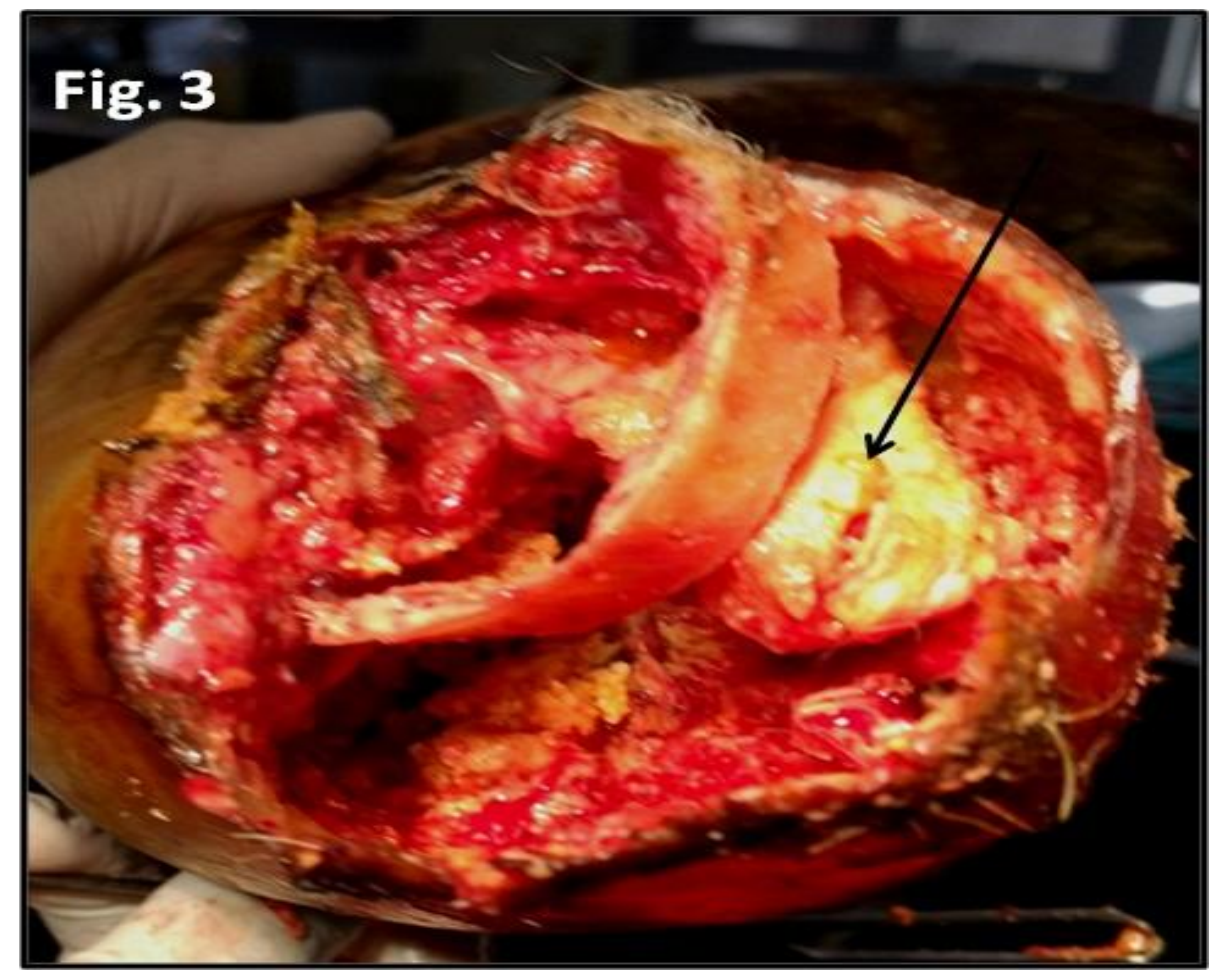

Fig.4 Photograph showing the normal wound healing on the 10th post-operative day

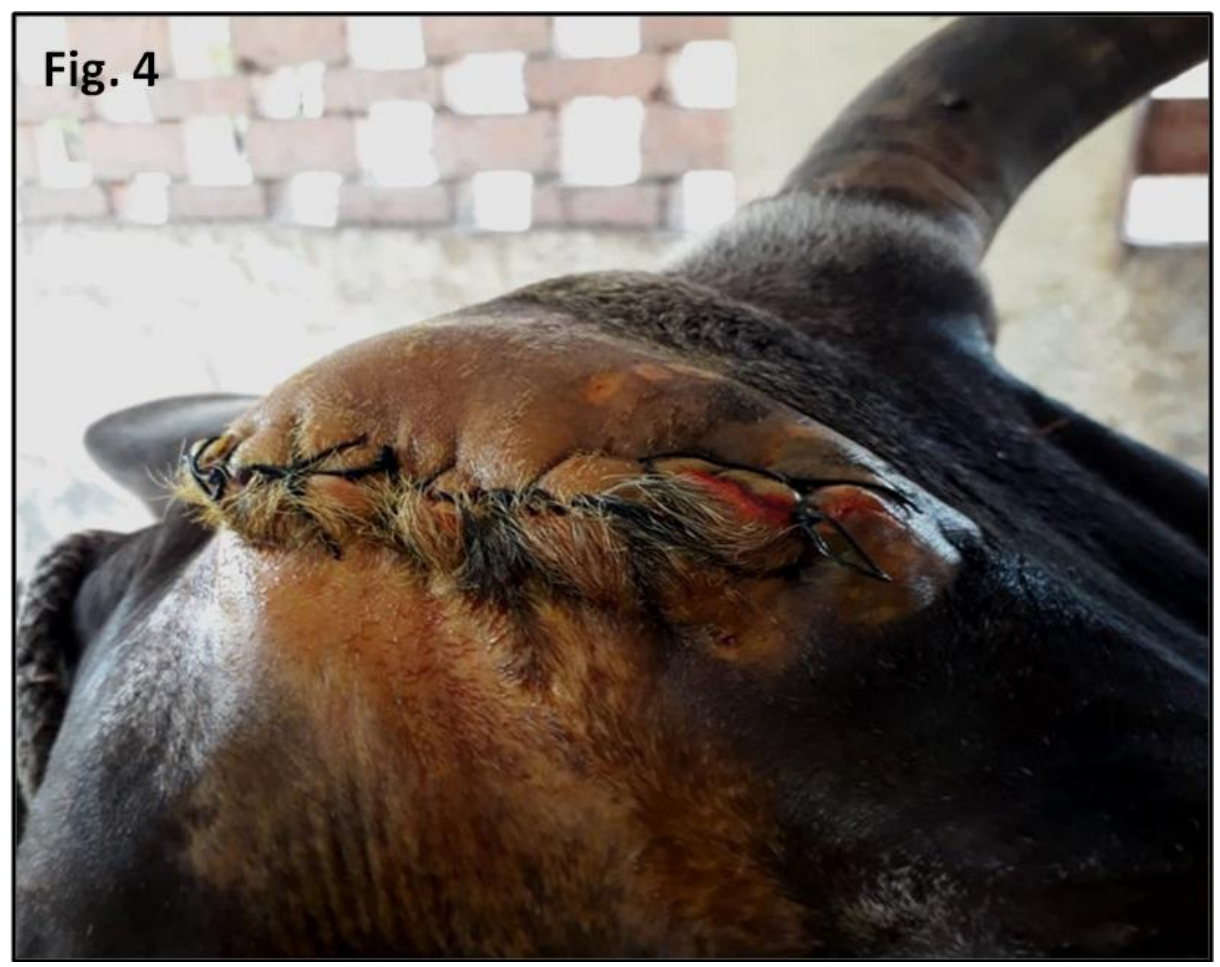


This difficulty was achieved by chiseling the underlying bone and subcutaneous dissection of the available skin. General anesthesia for the amputation was pain free for the bullock. The amputation helped in relieving the pain of the old bullock as it was increasing the weight on one side. Suction apparatus can be suitable employed for proper flushing of frontal sinuses during horn amputation. Early amputation of diseased horn is always beneficial for skin closure and bear better prognosis.

In conclusion, unilateral horn amputation for a squamous cell carcinoma can be successfully attempted under general anesthesia.

\section{Acknowledgement}

The authors duly acknowledge Indian Council of Agricultural research (ICAR-22), "All India network program on diagnostic imaging and management of surgical conditions in animals" for the completion of this study.

\section{References}

Behera, S.S., Nayak, S and Behera, M. 2016. Surgical Management of Squamous Cell Carcinoma of Horn in a Cow. IntasPolivet Vol.17 (II): 241-242.

Giri, D.K., Kashyap, D.K, Dewangan, G, Tiwari, S.K, Ghosh, R.C and Sinha, B. 2011.Squamous cell carcinoma of horn and its surgical management - a report of three cases. Int. J. Livest Res. 1:55-58.

Jaiswal, S., Singh, H.N, Kumar, S and Jadon, N.S. 2014. Horn Cancer - A clinical insight into its Diagnosis and Management in 10 cattle. IntasPolivet.Vol.15 (1): 3-6

Joshi, B.P., Soni, P.B, Ferar, D.T, Ghodasara, D.J and Prajapati, K.S. 2009. Epidemiological and pathological aspects of horn cancer in cattle of Gujarat. Indian J. Field Vet. 5: 15-
18.

Kumar, A. 2005. Veterinary Surgical Techniques, 2nd Edn., Vikas Publishing House Pvt. Ltd. New Delhi. pp. 217-19.

Kumar, V., Mathew, D.D, Kumar, N and Arya, R.S. 2013. Horn cancer in Bovines and its Management. IntasPolivet Vol. 14 (1): 5657

Lall, H.K. 1953. Incidence of horn cancer in Meerut Circle, Uttar Pradesh. Indian Vet. J. 30: 205-209.

Nicholas, H.B and Mc Donald L.E 2001. Jones Veterinary Pharmacology and Therapeutics. 6th Edn. Kaltani Printings, New Delhi.pp.874

Patra, B.N. 1963. Horn cancer in cattle. India. Vet. Rec. 71: 216.

Pitlawar, S.S., Gahlot, B.M, Akhare, S.B, Upadhye, S.V and Jadhao, P.T. 2016. Surgical Management of Horn Affections A Report of 2 Bullocks. IntasPolivet Vol.17 (II): 239-240.

Sastry, G.A., 2001. Veterinary Pathology. $7^{\text {th }}$ Edn, CBS Publisher and Distributors. New Delhi. pp. 205-249.

Sharma, N., and Singh, D. 2014. Unilateral Horn Cancer in a Bullock and its Management. IntasPolivet.Vol.15 (1): 7-8.

Tyagi, R.P.S., and Singh, J. 2006. Ruminant Surgery, $1^{\text {st }}$ Edn, CBS Publisher and Distributors. New Delhi. pp. 415-416.

Udharwar, S.V., Aher, V.D, Yadav, G.U, Bhikane, A.U and Dandge, B.P. 2008. Study on incidence, predisposing factors, symptomatology and treatment of horn cancer in bovine with special reference to surgery and chemotherapy. Vet. World. 1: 7-9.

Veena, P., Kumar, R.V.S, Sankar, P, Dhanalakshmi, N and Kokila, S. 2011. Squamous cell carcinoma of horn in a bullock- A case report. Ind. J. Anim Res. 45: $226-227$

\section{How to cite this article:}

Harmanpreet Singh Sodhi and Vandana Sangwan. 2019. Successful Horn Amputation for the Treatment of Horn Cancer in an 18 Year Old Humped Bullock. Int.J.Curr.Microbiol.App.Sci. 8(08): 537-541. doi: https://doi.org/10.20546/ijcmas.2019.808.063 